\title{
Low fruit and vegetable intake is associated with poor self- rated health in the Czech part of the HAPIEE study
}

Author names and affiliations

Eliska Hrezova1 (eliska.hrezova@recetox.muni.cz), Martin Bobak'1,2 (m.bobak@ucl.ac.uk), Nadezda Capkova ${ }^{3}$ (nadezda.capkova@szu.cz), Denes Stefler² (denes.stefler@ucl.ac.uk), Hynek Pikhart ${ }^{1,2}$ (h.pikhart@ucl.ac.uk)

${ }^{1}$ Research Centre for Toxic Compounds in the Environment, Faculty of Science, Masaryk University, Kamenice 753/5, D29, 62500 Brno, Czech Republic

${ }^{2}$ Research Department of Epidemiology and Public Health, University College London, 1-19 Torrington Place, London WC1E 7HB, United Kingdom

${ }^{3}$ The National Institute of Public Health, Šrobárova 49/48, 10000 Praha, Czech Republic

Corresponding author

Eliska Hrezova

E-mail: eliska.hrezova@recetox.muni.cz

Masaryk University

Research Centre for Toxic Compounds in the Environment, Faculty of Science Kamenice 753/3, D29, 62500 Brno

Czech Republic 


\section{Abstract}

Background:

Although fruits and vegetables are considered a pillar of healthy eating, previous evidence suggests that their consumption in Eastern European countries is low, and their association with health outcomes has rarely been researched in this region.

Aim:

To examine the effect of fruit and vegetable intake on self-rated health (SRH) in the Czech arm of the Health Alcohol and Psychosocial factors in Eastern Europe prospective cohort study.

Methods:

Dietary data on fruit and vegetable intake was measured at baseline using food frequency questionnaires, and $\mathrm{SRH}$ from the second wave was chosen as the main outcome. The relationship between fruit and vegetable intake and SRH was analyzed using multivariable ordinal regression.

Results:

A total of 4,255 persons aged 45-69, in good and very good SRH at baseline were included in the longitudinal analysis, with a median follow-up time of 3.7 years. In the second wave, $218(5.1 \%)$ individuals reported poor or very poor SRH. In the fully adjusted model, individuals in the lowest fruit and vegetable intake quartile had higher odds of poor SRH compared to those in the highest quartile (OR=1.24, 95\% Cl: $1.01-$ 1.52). When examined separately, the results were similar: for vegetables $(O R=1.25$, 95\% Cl: $1.03-1.51)$ and fruit (OR=1.18, 95\% Cl: 0.97-1.44).

Conclusion:

The observed longitudinal association suggests that low fruit and vegetable intake is associated with poor SRH in the Czech Republic. Considering almost half of our sample reported less than the daily recommended intake of 400 grams of fruits and vegetables, higher consumption should be supported.

\section{Key words}

Fruit and vegetable intake, Self-rated health, Lifestyle, Nutrition, Multivariable ordinal regression 
Abbreviations

A - Angina

EHIS - European Health Interview Survey

FFQ - Food Frequency Questionnaire

HA - Heart Attack

HAPIEE - Health, Alcohol, and Psychosocial Factors in Eastern Europe

IHD - Ischaemic Heart Disease

MI - Myocardial Infarction

MJ - Megajoule

NCDs - Non-communicable diseases

Q - Quartile

SRH - Self-rated health 


\section{Introduction}

Fruits and vegetables are among the fundamental pillars of healthy eating and considered one of the key factors in preventing non-communicable diseases (NCDs) and death worldwide (Micha et al., 2017). A systematic analysis of the Global Burden of Disease study identified an optimal intake of 250 grams of fruit and 360 grams of vegetable per day in preventing NCDs (GBD 2017 Diet Collaborators, 2019) and the World Health Organization recommends the consumption of at least 400 grams or five servings of fruit and vegetable per day (World Health Organization, 2003).

Self-reported health (SRH) is an extensively used instrument for measuring health at the individual level (Bombak, 2013; Bowling, 2005). The instrument's popularity is mainly due to its simplicity, easy administration, and ability to predict future health status and mortality (Bamia et al., 2017; DeSalvo et al., 2006; Idler and Benyamini, 1997; Mossey and Shapiro, 1982). Previous research has identified several factors that can influence $\mathrm{SRH}$, including objective health status, socioeconomic status (Huisman et al., 2007; Dowd and Zajacova, 2007; Bobak et al., 2000), psychosocial factors (Molarius et al., 2007;), and lifestyle factors such as physical activity (Han, 2021; Abu-Omar et al., 2004;), smoking (Chen et al., 2007), or alcohol consumption (Lindström et al., 2020; Zhao et al., 2020; Gémes et al., 2019).

The association of fruit and vegetable intake with $\mathrm{SRH}$ has also been investigated by previous research. Several cross-sectional studies have described the positive association between fruit and vegetable intake and self-rated health (Abuladze et al., 2017; Takaoka and Kawakami, 2013; Södergren et al., 2012; Lengyel et al., 2009; Kim et al., 2008). Additionally, the relationship between fruit and vegetable intake and SRH has also been analyzed in prospective studies, emphasizing the positive effect of vegetables on SRH (Mood, 2013).

Literature regarding nutrition or fruit and vegetable intake and their relationship with health remains sparse in Central and Eastern Europe, and no previous study in the region examined the association with $\mathrm{SRH}$ in a longitudinal manner. According to the European Health Interview Survey (EHIS), only 5\% Czech men and 12\% women between the age of 45 and 64 consume five or more servings of fruits and vegetables 
a day, and almost half of the population in this age group does not consume fruits or vegetables at all on a daily basis (EUROSTAT, 2020a). Simultaneously, the Czech Republic was found to be one of the countries with a highest rate of poor $\mathrm{SRH}$, with 9.5\% men and 9.6\% women aged 45-64 reporting SRH as bad or very bad (EUROSTAT, 2020b).

The primary goal of this analysis was to examine fruit and vegetable intake and its relationship with SRH in the Czech part of the Health, Alcohol, and Psychosocial Factors in Eastern Europe (HAPIEE) study.

\section{Materials and Methods}

The HAPIEE study is an international prospective cohort study focusing on social, psychosocial, and lifestyle factors and the health of the urban population in Central and Eastern Europe. The first wave of data collection in the study's Czech arm took place between 2002 and 2005, and a total of 8,856 persons aged 45-69 years were recruited in seven cities (Hradec Králové, Jihlava, Havířov, Karviná, Kroměříž, Liberec and Ústí nad Labem). All participant completed a questionnaire survey and underwent a detailed medical examination, including blood sampling (Peasey et al., 2006). The second wave took place between 2006 and 2008, with the participation of 5,210 individuals from the original sample.

Only individuals who participated in both waves were included in this analysis. From them, we excluded those with missing data on $\mathrm{SRH}$ from both waves $(n=36)$, those with poor and very poor SRH from wave1 $(n=474)$, and those with missing data on fruit and vegetable intake $(n=445)$. Data on a total of 4,255 individuals were included in the analysis. Informed consent was obtained from all participants, and the study was approved by the University College London Ethics Committee and The National Institute of Public Health in the Czech Republic.

\section{Measures}

The collection of nutritional data in the HAPIEE study is described in detail previously (Boylan et al., 2009). Daily fruit and vegetable intake was measured using the Food Frequency Questionnaire (FFQ). Participants reported how often they consumed selected foods and beverages on a nine-point frequency scale from never or less than 
once a month to six or more times a day. The FFQ consists of 136 items, 23 and 29 items in the fruit and vegetable group, respectively (Supplementary material, Table S1). Daily consumption of individual fruits and vegetables was calculated by multiplying the number of servings per day by the average portion size. The total daily consumption of each participant was then calculated by adding up the individual items. As a result, we obtained continuous variables of daily consumption of fruit and daily vegetable consumption. Estimating total intake using FFQ may not be accurate, especially for fruit and vegetables. There is particularly a risk of overestimating actual consumption due to social desirability bias (Miller et al., 2008). The FFQ used in HAPIEE was thus validated on a randomly selected smaller sample of participants (Stefler et al., 2014), estimating the correlation between consumption of fruit and vegetable and plasma biomarkers (vitamin $\mathrm{C}$ and beta carotene).

The primary outcome, $\mathrm{SRH}$, was measured by the question: "In the last 12 months, would you say that your health was: very good, good, average, poor, and very poor?" Other sociodemographic and lifestyle variables were also considered in the analysis, including education (primary or less, vocational, secondary, university), economic activity (employed, entrepreneur, pensioner still employed, a pensioner not employed, housewife/unemployed), marital status (married or cohabiting, single, divorced, widowed), material deprivation measured by the availability of enough money for food, clothing, and paying bills (each question with answers on Likert scale $0-4$, with overall maximum deprivation score of 12 categorized as, without problems: score 0 , few problems: score 1 to 2, with problems: score 3 and more), smoking status (non-, ex-, current smokers), binge drinking of alcohol (60 $\mathrm{g}$ of ethanol more than once a month), and physical activity (number of hours a week engage in sports, games or hiking categorized as, no activity: 0 hours per week, low: 1 to 2 hours per week, mild: 3 to 5 hours per week, intensive: more than 6 hours per week). Finally, the health status was measured by questions on self-reported doctor diagnosed high blood pressure (yes, no), diabetes mellitus (yes, no), as well as questions on previous heart attack/acute myocardial infarction, angina/ischemic heart disease, stroke, cancer), and long-term health problems that needed medical treatment. 


\section{Statistical analysis}

Ordinal regression models were used to examine longitudinal associations between fruit and vegetable intake from wave 1 and response to the $\mathrm{SRH}$ question from wave 2. We classified fruit, vegetable and combined fruit and vegetable intakes into quartiles $(Q)$, and the ordinal regression models were adjusted for other independent variables. Model 1 looked at the relationship between the $\mathrm{SRH}$, the main exposure variables, adjusted for age and sex. We further adjusted for education, economic activity, marital status, material deprivation, smoking status, binge drinking of alcohol, and physical activity, and the variables related to health status in wave 1 in Model 2. Finally, in Model 3, we added the total energy intake in megajoule (MJ), and SRH from wave 1.

To determine the possible effect of sex as a moderator of our hypothesized effect, we tested possible interactions between the nutritional variables and sex. There was no evidence for statistically significant interaction (for fruit intake, vegetable intake; the homogeneity $p$-values were $0.365,0.167$, respectively). Thus, men and women were assessed together in all models. Statistical analysis was calculated using IBM SPSS Statistics 25 with a selected significance level of 0.05 .

\section{Results}

Sociodemographic characteristic and self-rated health Data on SRH and fruit and vegetable consumption were available from a total of 4,255 men and women. Most participants rated their health as average (34.9\%) and good $(51.8 \%)$ while 204 individuals $(4.8 \%)$ rated their health as poor and $14(0.3 \%)$ as very poor. Table 1 shows the distribution of the individual's characteristics across fruit and vegetable intake quartiles. Increased fruit and vegetable intake were positively associated with being female, primary or less and secondary education, being widowed, and employed/not employed pensioners. Furthermore, it was positively associated with non-smokers, non-drinkers, and individuals with medium and intensive physical activity.

Regression analysis of $\mathrm{SRH}$ and fruit and vegetable intake Table 2 shows the odds ratios for all three models, exposure variables, and $p$-value for a trend in fruit and vegetable consumption categories. We chose Q4 as the reference 
category, and thus with decreasing consumption of fruit and vegetable, there were higher odds of worse $\mathrm{SRH}$. We also observed increasing odds of worse health across decreasing consumption of combined fruit and vegetable intake in the fully adjusted model (Model 3). Those who consumed the least fruits and vegetables had significantly higher odds of worse $\mathrm{SRH}$ compared to those who consumed the most $(\mathrm{OR}=1.24, \mathrm{Cl}: 1.01-1.52)$. Similarly, vegetable intake predicted worse $\mathrm{SRH}$ for individuals with less consumption ( $\mathrm{OR}=1.25, \mathrm{Cl}$ : 1.03-1.51). After controlling for all confounders, there was no effect of fruit intake on SRH ( $p$ value for trend 0.239 ).

The associations with other covariates were similar for fruit and vegetable separately, as for the merged category. For combined fruit and vegetable intake (Supplementary materials, Table S2) in a fully adjusted Model 3, odds for worse SRH were negatively associated with primary or less education ( $\mathrm{OR}=1.36)$, non-working pensioner $(\mathrm{OR}=1.39)$, with problems in the area of material deprivation $(\mathrm{OR}=1.25)$, no physical activity $(\mathrm{OR}=1.19)$ and with high blood pressure, diabetes and long-term health problems $(\mathrm{OR}=1.36, \mathrm{OR}=1.59, \mathrm{OR}=1.47)$. Unsurprisingly, we saw an adverse association $\mathrm{SRH}$ from wave 1 , in the good and very good category $(\mathrm{OR}=0.25$, $\mathrm{OR}=0.04$ ) compared to average $\mathrm{SRH}$. There was no association between age, sex, smoking status, total energy intake, and variables asking individuals about diagnose and hospitalization for health conditions.

\section{Discussion}

\section{Main findings}

In this study, we analyzed the longitudinal relationship of fruit and vegetable intake with $\mathrm{SRH}$ in an urban general population sample in the Czech Republic. We found that lower consumption of fruits and vegetables was associated with worse $\mathrm{SRH}$. The association was statistically significant for vegetable intake and when fruit and vegetable intakes were merged, but not when fruit intake was assessed separately, although the direction of the effect was consistent with the other two outcomes. Poor $\mathrm{SRH}$ was also associated with primary or less education, non-working pensioner, materially deprived, not physically active, with high blood pressure, diabetes, and longterm health problems. 


\section{Interpretation of findings}

Findings for the relationship between $\mathrm{SRH}$ and fruit and vegetable intake are consistent with previous literature, where generally higher risk of worse $\mathrm{SRH}$ with lower fruit and vegetable intakes were observed in cross-sectional (Abuladze et al. 2017, Södergren et al., 2012) as well as in longitudinal studies (Mood, 2013, Takaoka and Kawakami, 2013, Lengyel et al., 2009). A randomized control trial in Germany examined the association between several risk factors, including low fruit and vegetable intake, and $\mathrm{SRH}$ in a specific population group, and found that low consumption (less than five servings of fruits and vegetables per day) was significantly associated with poor SRH, but only for women (Freyer-Adam et al., 2011).

Individuals possibly assess their health based on health status and their own health behavior (Jylhä, 2009). Taking into account high fruit and vegetable intake can affect both pathways. Fruits and vegetables are sources of beneficial substances such as vitamins, minerals, other bioactive substances, or fiber. All of these are biologically active components and may play a role in preventing the development of cardiovascular and other chronic diseases (Wang et al., 2014). The SRH may also reflect the awareness of an individual's health behavior (Bombak, 2013). Eating fruits and vegetables is considered beneficial for one's perception of own health; thus, higher consumption of fruits and vegetables may lead to a better SRH. Many other factors are reflected in SRH, so characteristics, such as primary or less education, non-working pensioner, materially deprived with no physical activity, high blood pressure, diabetes mellitus, and long-term health problems, were also associated with poor SRH. However, nutrition is a modifiable risk factor for chronic health conditions, and a healthy diet should be emphasized. According to WHO, the recommended daily intake of fruits and vegetables is more than 400 grams as a part of a healthy diet (World Health Organization, 2003), and the Czech dietary guidelines are even higher (600 grams of fruits and vegetables a day) (The Czech Society for Nutrition, 2012). Almost half of our sample did not meet the threshold set by the WHO recommendation, and only a small minority consumed more than $600 \mathrm{~g} /$ day. Therefore, we should promote and encourage higher consumption of fruits and vegetables, especially in mid and older age groups. Our results suggest that higher intakes could lead to better self-perceived health in the population and could potentially contribute to improved population health in the Czech Republic. 
Our results are also consistent with previous studies that showed strong relationships of fruit and vegetable intake with socioeconomic factors or other lifestyle habits (Amini et al., 2021; Estaquio et al., 2008; De Irala-Estévez et al., 2000) which may confound the association with SRH. Low education or unemployment, for example, can lead to lower fruit and vegetable intake due to financial constraints, while these factors are also often predictors of low SRH (Lindholm et al., 2001). Taking into account these relationships with multivariable adjusted models is important for the validity of the findings.

\section{Limitations and strengths}

The presented study has several limitations. We used data from FFQ, which is a retrospective method, and the estimated quantity may be imprecise and over/underestimated. In fact, overestimation of fruit intake with FFQ could be up to 40\% compared to 24-hr recall (Michels et al., 2005, Kristal et al., 2005). However, FFQ offers a detailed record of an individual's diet, and future analysis could follow the relationship of specific fruits and vegetables on $\mathrm{SRH}$.

Another possible limitation is a reduction of the study sample in the second wave. Due to the drop-out, exclusion of individuals with poor and very poor SRH from wave one, and missing data on fruit and vegetable intake, we analyze the effect on only half of the original sample. We have compared those included in the analysis and those who did not participate in the second wave. Non-participants were younger, had a higher proportion of less-educated individuals, unemployed pensioners, and more materially deprived individuals. Similarly, individuals with poor or very poor SRH in wave 1, and therefore excluded from the main analysis, were less educated, more likely to be unemployed pensioners, and more deprived. In addition, they have the highest proportion of no physically active participants. These groups are more difficult to keep participating in prospective studies (Cheung et al., 2017; Jooste et al., 1990). Considering the fact that participants were recruited only from mid-sized towns, the findings may not be entirely representative of the Czech population as a whole. To avoid residual confounding, we adjusted for a large number of possible confounders such as socioeconomic and individual's health status characteristics, but we cannot exclude potential effect of some unmeasured variables. 
Apart from the methodological issues and limitations discussed above, our study added new longitudinal findings to strengthen the available evidence on associations between fruit and vegetable intake and SRH. Furthermore, the HAPIEE study is the most extensive study of its kind in the Czech Republic and Eastern Europe. It collects and is a source of detailed data about dietary habits and all socioeconomic factors and creates a reliable and information-rich database for the population's long-term study.

\section{Conclusion}

In conclusion, we examined the longitudinal relationship between SRH and fruit and vegetable intake. The observed association suggests that low consumption of fruits and vegetables may lead to worse SRH. Considering the previous evidence regarding low intake of fruits and vegetables in the Czech Republic and other Eastern European countries, public health nutritional interventions that aim to increase dietary intakes of these foods have the potential to improve population health in this region. 


\section{Acknowledgement}

We would like to thank all the participants for their long-term support and Tomas Prusa for his help in the paper preparation.

\section{Author's Contributions}

$\mathrm{EH}$ and HP conceived the analytical design for this manuscript. MB, NC, and HP conceived the overall study design for the HAPIEE study and oversaw data collection. EH carried out data analysis, HP and DS advised on data analysis. EH drafted the initial version of the manuscript. All authors were involved in writing the paper and had final approval of the submitted manuscript.

\section{Declaration of Conflicting Interests}

The Authors declare that there is no conflict of interest.

\section{Ethical Statement}

Informed consent was obtained from all participants, and the study was approved by the University College London Ethics Committee and The National Institute of Public Health in the Czech Republic.

\section{Funding}

The author(s) disclosed receipt of the following financial support for the research, authorship, and/or publication of this article: The HAPIEE study was supported by the Wellcome Trust (grant numbers WT064947, WT081081); the US National Institute of Aging (grant number 1RO1AG23522) and the MacArthur Foundation Initiative on Social Upheaval and Health; CETOCOEN EXCELLENCE Teaming 2 project supported by Horizon2020 (grant number 857560) and the Czech Ministry of Education, Youth and Sports (grant number CZ.02.1.01/0.0/0.0/18_046/0015975), RExposome Chair project supporter by Horizon2020 (grant number 857487). The funders of the study had no role in study design, data collection, analysis, and interpretation, or writing of the manuscript. 


\section{References}

Abuladze L, Kunder N, Lang K, et al. (2017) Associations between self-rated health and health behaviour among older adults in Estonia: a cross-sectional analysis. British Medical Journal 7(6): e013257.

Abu-Omar K, Rütten A and Robine JM (2004) Self-rated health and physical activity in the European Union. Social and Preventive Medicine 49(4): 235-242.

Amini M, Najafi F, Karyani AL, et al. (2021) Does socioeconomic status affect fruit and vegetable intake? Evidence from a cross-sectional analysis of the RaNCD Cohort. International Journal of Fruit Science 21(1): 779-790.

Bamia C, Orfanos P, Juerges H, et al. (2017) Self-rated health and all-cause and cause-specific mortality of older adults: Individual data meta-analysis of prospective cohort studies in the CHANCES Consortium. Maturitas 103: 37-44.

Bobak M, Pikhart H, Rose R, et al. (2000) Socioeconomic factors, material inequalities, and perceived control in self-rated health: cross-sectional data from seven post-communist countries. Social Science \& Medicine 51(9): 1343-1350.

Bombak AE (2013) Self-Rated Health and Public Health: A Critical Perspective. Frontiers in Public Health 1(May): 48-51.

Bowling A (2005) Just one question: If one question works, why ask several? Journal of epidemiology and community health 59(5): 342-345.

Boylan S, Welch A, Pikhart H, et al. (2009) Dietary habits in three Central and Eastern European countries: The HAPIEE study. BMC Public Health 9: 1-13.

De Irala-Estévez J, Groth M, Johansson L, et al. (2000) A systematic review of socioeconomic differences in food habits in Europe: consumption of fruit and vegetables. European Journal of Clinical Nutrition 54(9): 706-714.

DeSalvo KB, Bloser N, Reynolds K, et al. (2006) Mortality prediction with a single general self-rated health question. Journal of General Internal Medicine 21(3): 267-275.

Dowd JB and Zajacova A (2007) Does the predictive power of self-rated health for subsequent mortality risk vary by socioeconomic status in the US? International Journal of Epidemiology 36(6): 1214-1221.

EUROSTAT (2020a) Daily consumption of fruit and vegetables by sex, age and educational attainment level. Available at:

https://ec.europa.eu/eurostat/databrowser/view/HLTH_EHIS_FV3E_custom_351 259/default/table?lang=en (accessed 12 June 2021).

EUROSTAT (2020b) Self-perceived health by sex, age and income quintile. Available at: https://ec.europa.eu/eurostat/databrowser/bookmark/9dbe9e0a-b083-432299ad-4bfe9f6502e4?lang=en (accessed 12 June 2021). 
Estaquio C, Druesne-Pecollo N, Latino-Martel P, et al. (2008) Socioeconomic Differences in Fruit and Vegetable Consumption among Middle-Aged French Adults: Adherence to the 5 A Day Recommendation. Journal of the American Dietetic Association 108(12): 2021-2030.

Freyer-Adam J, Gaertner B, Tobschall S, et al. (2011) Health risk factors and selfrated health among job-seekers. BMC public health 11: 659 .

GBD 2017 Diet Collaborators (2019) Health effects of dietary risks in 195 countries, 1990-2017: a systematic analysis for the Global Burden of Disease Study 2017. Lancet 393(10184): 1958-1972.

Gémes K, Moeller J, Engström K, et al. (2019) Alcohol consumption trajectories and self-rated health: findings from the Stockholm Public Health Cohort. BMJ Open 9(8): e028878.

Han S (2021) Physical activity and self-rated health: role of contexts. Psychology, Health \& Medicine 26(3): 347-358.

Huisman M, Van Lenthe F and Mackenbach J (2007) The predictive ability of selfassessed health for mortality in different educational groups. International Journal of Epidemiology 36(6): 1207-1213.

Chen H, Cohen P and Kasen S (2007) Cohort Differences in Self-Rated Health: Evidence from a Three-Decade, Community-Based, Longitudinal Study of Women. American Journal of Epidemiology 166(4): 439-446.

Cheung KL, Ten Klooster P, Smit C, et al. (2017) The impact of non-response bias due to sampling in public health studies: A comparison of voluntary versus mandatory recruitment in a Dutch national survey on adolescent health. $B M C$ Public Health 17(1): 1-10.

Idler EL and Benyamini Y (1997) Self-Rated Health and Mortality: A Review of TwentySeven Community Studies. Journal of Health and Social Behavior 38(1): 21-37.

Jooste PL, Yach D, Steenkamp HJ, et al. (1990) Drop-out and newcomer bias in a community cardiovascular follow-up study. International Journal of Epidemiology 19(2): 284-289.

Jylhä M (2009) What is self-rated health and why does it predict mortality? Towards a unified conceptual model. Social Science \& Medicine 69(3): 307-316.

Kim MJ, Lim YR and Kwak HK (2008) Dietary behaviors and body image recognition of college students according to the self-rated health condition. Nutrition research and practice 2(2): 107-113.

Kristal AR, Peters U and Potter JD (2005) Is it time to abandon the food frequency questionnaire? Cancer Epidemiology Biomarkers and Prevention 14(12): 28262828. 
Lindholm C, Burström B and Diderichsen F (2001) Does chronic illness cause adverse social and economic consequences among Swedes? Scandinavian Journal of Public Health 29(1): 63-70.

Lindström J, Hellström Ch, Simonsson B, et al. (2020) Alcohol consumption and selfrated health among older people: population-based study in Sweden. Journal of Public Health 42(4): 756-765.

Lengyel CO, Tate RB and Obirek Blatz AK (2009) The Relationships Between Food Group Consumption, Self-Rated Health, and Life Satisfaction of CommunityDwelling Canadian Older Men: The Manitoba Follow-Up Study. Journal of Nutrition for the Elderly 28(2): 158-173.

Micha R, Shulkin ML, Peñalvo JL, et al. (2017) Etiologic effects and optimal intakes of foods and nutrients for risk of cardiovascular diseases and diabetes: Systematic reviews and meta-analyses from the Nutrition and Chronic Diseases Expert Group (NutriCoDE). PloS one 12(4): e0175149.

Michels KB, Welch AA, Luben R, et al. (2005) Measurement of fruit and vegetable consumption with diet questionnaires and implications for analyses and interpretation. American journal of epidemiology 161(10): 987-94.

Miller TM, Abdel-Maksoud MF, Crane LA, et al. (2008) Effects of social approval bias on self-reported fruit and vegetable consumption: A randomized controlled trial. Nutrition Journal 7(1): 1-7.

Molarius A, Berglund K, Eriksson C, et al. (2007) Socioeconomic conditions, lifestyle factors, and self-rated health among men and women in Sweden. The European Journal of Public Health 17(2): 125-133.

Mood C (2013) Life-style and self-rated global health in Sweden: A prospective analysis spanning three decades. Preventive Medicine 57(6): 802-806.

Mossey JM and Shapiro E (1982) Self-rated health: a predictor of mortality among the elderly. American journal of public health 72(8): 800-808.

Peasey A, Bobak M, Kubinova R, et al. (2006) Determinants of cardiovascular disease and other non-communicable diseases in Central and Eastern Europe: Rationale and design of the HAPIEE study. BMC Public Health 6(1): 255.

Södergren M, McNaughton SA, Salmon J, et al. (2012) Associations between fruit and vegetable intake, leisure-time physical activity, sitting time and self-rated health among older adults: Cross-sectional data from the WELL study. BMC Public Health 12(1): 551.

Stefler D, Pikhart H, Jankovic N, et al. (2014) Healthy diet indicator and mortality in Eastern European populations: Prospective evidence from the HAPIEE cohort. European Journal of Clinical Nutrition 68(12): 1346-1352. 
Takaoka Y and Kawakami N (2013) Fruit and vegetable consumption in adolescence and health in early adulthood: a longitudinal analysis of the statistics Canada's National Population Health Survey. BMC Public health 13: 1206.

The Czech Society for Nutrition (2012) Dietary Guidelines for the Population of the Czech Republic. Available at: www.vyzivaspol.cz/vyzivova-doporuceni-proobyvatelstvo-ceske-republiky (accessed 23 October 2021).

Wang X (2014) Fruit and vegetable consumption and mortality from all causes, cardiovascular disease, and cancer: systematic review and dose-response metaanalysis of prospective cohort studies. British Medical Journal 349: g4490.

World Health Organization (2003) Joint WHO/FAO Expert Consultation on Diet, Nutrition and the Prevention of Chronic Diseases. In: Geneva, Switzerland, 28 January-1 February 2002, pp. 89. Geneva: World Health Organization.

Zhao J, Sun H, Ma Y, et al. (2020) Association of self-reported health with alcohol consumption: a study conducted among Chinese and Canadian middle-aged and older adults. China Population and Development Studies 4(1): 58-97. 


\section{Tables}

Table 1 Distribution of the individuals across fruit and vegetable intake quartiles

\begin{tabular}{|c|c|c|c|c|c|}
\hline \multicolumn{2}{|c|}{ Fruit and vegetable intake quartiles } & $\begin{array}{c}\text { Q1 } \\
(n=1,010)\end{array}$ & $\begin{array}{c}\text { Q2 } \\
(n=1,094) \\
\end{array}$ & $\begin{array}{c}\text { Q3 } \\
(n=1,086) \\
\end{array}$ & $\begin{array}{c}\text { Q4 } \\
(n=1,065)\end{array}$ \\
\hline \multicolumn{2}{|c|}{ Fruit and vegetable intake g/day } & $<293.46$ & $293.47-463.71$ & $463.72-713.72$ & $>713.72$ \\
\hline \multicolumn{2}{|c|}{ Sex, female $(\%)$} & $383(37.9)$ & $508(46.6)$ & $674(62.1)$ & $775(72.8)$ \\
\hline \multirow[t]{6}{*}{ Age (\%) } & $45-49$ & $188(18.6)$ & $173(15.8)$ & $150(13.8)$ & $168(15.8)$ \\
\hline & $50-54$ & $222(22.0)$ & $219(20.0)$ & $187(17.2)$ & $198(18.6)$ \\
\hline & $55-59$ & $204(20.2)$ & $240(21.9)$ & $207(19.1)$ & $206(19.3)$ \\
\hline & $60-64$ & $219(21.7)$ & $250(22.9)$ & $294(27.1)$ & $258(24.2)$ \\
\hline & $65-69$ & $176(17.4)$ & $212(19.4)$ & $247(22.7)$ & $234(22.0)$ \\
\hline & $\mathrm{N} / \mathrm{A}$ & $1(0.1)$ & $0(0.0)$ & $1(0.1)$ & $1(0.1)$ \\
\hline \multirow[t]{5}{*}{ Education (\%) } & Primary or less & $83(8.2)$ & $88(8.0)$ & $101(9.3)$ & $110(10.3)$ \\
\hline & Vocational & $374(37.0)$ & $381(34.8)$ & $334(30.8)$ & $337(31.6)$ \\
\hline & Secondary & $366(36.2)$ & $442(40.4)$ & $455(41.9)$ & $463(43.5)$ \\
\hline & University & $179(17.7)$ & $180(16.5)$ & $194(17.9)$ & $152(14.3)$ \\
\hline & $\mathrm{N} / \mathrm{A}$ & $8(0.8)$ & $3(0.3)$ & $2(0.2)$ & $3(0.3)$ \\
\hline \multirow[t]{6}{*}{ Economic activity } & Employed & $432(42.8)$ & $456(41.7)$ & $377(34.7)$ & $372(34.9)$ \\
\hline & Entrepreneur & $108(10.7)$ & $86(7.9)$ & $75(6.9)$ & $86(8.1)$ \\
\hline & $\begin{array}{l}\text { Pensioner, still } \\
\text { employed }\end{array}$ & $90(8.9)$ & $98(9.0)$ & $101(9.3)$ & $102(9.6)$ \\
\hline & $\begin{array}{l}\text { Pensioner, not } \\
\text { employed }\end{array}$ & $341(33.8)$ & $416(38.0)$ & $498(45.9)$ & $475(44.6)$ \\
\hline & $\begin{array}{l}\text { Housewife, } \\
\text { unemployed }\end{array}$ & $30(3.0)$ & $27(2.5)$ & $27(2.5)$ & $22(2.1)$ \\
\hline & $\mathrm{N} / \mathrm{A}$ & $9(0.9)$ & $11(1.0)$ & $8(0.7)$ & $8(0.8)$ \\
\hline \multirow[t]{5}{*}{ Marital status (\%) } & Married/Cohabiting & $774(76.6)$ & $847(77.4)$ & $837(77.1)$ & $800(75.1)$ \\
\hline & Single & $35(3.5)$ & $23(2.1)$ & $27(2.5)$ & $22(2.1)$ \\
\hline & Divorced & $127(12.6)$ & $129(11.8)$ & $139(12.8)$ & $122(11.5)$ \\
\hline & Widowed & $69(6.8)$ & $92(8.4)$ & $80(7.4)$ & $119(11.2)$ \\
\hline & $\mathrm{N} / \mathrm{A}$ & $5(0.5)$ & $3(0.3)$ & $3(0.3)$ & $2(0.2)$ \\
\hline \multirow[t]{4}{*}{ Material deprivation (\%) } & Without problems & $492(48.7)$ & $566(51.7)$ & $577(53.1)$ & $563(52.9)$ \\
\hline & Few problems & $247(24.5)$ & $272(24.9)$ & $276(25.4)$ & $273(25.6)$ \\
\hline & With problems & $266(26.3)$ & $245(22.4)$ & $226(20.8)$ & $216(20.3)$ \\
\hline & $\mathrm{N} / \mathrm{A}$ & $5(0.5)$ & $11(1.0)$ & $7(0.6)$ & $13(1.2)$ \\
\hline \multirow[t]{4}{*}{ Smoking status (\%) } & Smoker & $317(31.4)$ & $248(22.7)$ & $233(21.5)$ & $209(19.6)$ \\
\hline & Ex-smoker & $291(28.8)$ & $341(31.2)$ & $305(28.1)$ & $275(25.8)$ \\
\hline & Non-smoker & $390(38.6)$ & $492(45.0)$ & $542(49.9)$ & $574(53.9)$ \\
\hline & $\mathrm{N} / \mathrm{A}$ & $12(1.2)$ & $13(1.2)$ & $6(0.6)$ & $7(0.7)$ \\
\hline \multirow[t]{2}{*}{ Binge drinking } & No & $694(68.7)$ & $804(73.5)$ & $856(78.8)$ & $882(82.8)$ \\
\hline & $\mathrm{N} / \mathrm{A}$ & $24(2.4)$ & $27(2.5)$ & $24(2.2)$ & $23(2.2)$ \\
\hline \multirow[t]{5}{*}{ Physical activity } & No activity & $361(35.7)$ & $264(24.1)$ & $241(22.2)$ & $195(18.3)$ \\
\hline & Low & $187(18.5)$ & $240(21.9)$ & $219(20.2)$ & $200(18.8)$ \\
\hline & Medium & $217(21.5)$ & $230(21.0)$ & $245(22.6)$ & $265(24.9)$ \\
\hline & Intensive & $222(22.0)$ & $339(31.0)$ & $356(32.8)$ & $382(35.9)$ \\
\hline & $\mathrm{N} / \mathrm{A}$ & $23(2.3)$ & $21(1.9)$ & $25(2.3)$ & $23(2.2)$ \\
\hline \multicolumn{2}{|c|}{ Mean energy intake $(\mathrm{SD})^{\star}$, MJ } & $7.25(2.37)$ & $8.07(2.45)$ & $8.58(2.50)$ & $10.21(3.17)$ \\
\hline \multirow[t]{2}{*}{ High blood pressure (\%) } & No & $613(60.7)$ & 637 (58.2) & $591(54.4)$ & $613(57.6)$ \\
\hline & $\mathrm{N} / \mathrm{A}$ & $3(0.3)$ & $1(0.1)$ & $2(0.2)$ & $4(0.4)$ \\
\hline
\end{tabular}




\begin{tabular}{|c|c|c|c|c|c|}
\hline Diabetes mellitus (\%) & No & $919(91.0)$ & $997(91.1)$ & $990(91.2)$ & $958(90.0)$ \\
\hline \multirow{3}{*}{$\begin{array}{l}\text { Long-term health } \\
\text { problems (\%) }\end{array}$} & $\mathrm{N} / \mathrm{A}$ & $3(0.3)$ & $2(0.2)$ & $2(0.2)$ & $3(0.3)$ \\
\hline & No & $479(47.4)$ & $508(46.4)$ & $443(40.8)$ & $444(41.7)$ \\
\hline & $\mathrm{N} / \mathrm{A}$ & $14(1.4)$ & $8(0.7)$ & $12(1.1)$ & $8(0.8)$ \\
\hline \multirow[t]{2}{*}{$\begin{array}{l}\text { Diagnosed/hospitalised } \\
\text { HA/MI** }(\%)\end{array}$} & No & $952(94.3)$ & $1024(93.6)$ & $1025(94.4)$ & 994 (93.3) \\
\hline & $\mathrm{N} / \mathrm{A}$ & $26(2.6)$ & $24(2.2)$ & $29(2: 7)$ & 35 (3.3) \\
\hline \multirow{2}{*}{$\begin{array}{l}\text { Diagnosed/hospitalised } \\
A / I H D^{* * *}(\%)\end{array}$} & No & $931(92.2)$ & $997(91.1)$ & $993(91.4)$ & $970(91.1)$ \\
\hline & $\mathrm{N} / \mathrm{A}$ & $29(2.9)$ & $25(2.3)$ & $31(2.9)$ & $34(3.2)$ \\
\hline \multirow[t]{2}{*}{$\begin{array}{l}\text { Diagnosed/hospitalised } \\
\text { stroke (\%) }\end{array}$} & No & $955(94.6)$ & $1041(95.2)$ & $1040(95.8)$ & $1005(94.4)$ \\
\hline & $\mathrm{N} / \mathrm{A}$ & $29(2.9)$ & $27(2.5)$ & $32(2.9)$ & $34(3.2)$ \\
\hline \multirow[t]{2}{*}{$\begin{array}{l}\text { Diagnosed/hospitalised } \\
\text { cancer }(\%)\end{array}$} & No & $941(93.2)$ & $1018(93.1)$ & $984(90.6)$ & $968(90.9)$ \\
\hline & $\mathrm{N} / \mathrm{A}$ & $27(2.7)$ & $27(2.5)$ & $33(3.0)$ & $34(3.2)$ \\
\hline
\end{tabular}

*Standard deviation

**Diagnosed/hospitalised for heart attack (HA)/acute myocardial infarction (MI)

${ }^{* * *}$ Diagnosed/hospitalised for angina (A)/ischaemic heart disease (IHD) 
Table 2 Results of ordinal regression analysis of SRH and fruit and vegetable intake (Models 1-3)

\begin{tabular}{|c|c|c|c|c|c|c|c|c|c|c|}
\hline & & \multicolumn{3}{|c|}{ Model 1} & \multicolumn{3}{|c|}{ Model 2} & \multicolumn{3}{|c|}{ Model 3} \\
\hline & & OR & Cl (95\%) & $p$ value & OR & $\mathrm{Cl}(95 \%)$ & $p$ value & OR & $\mathrm{Cl}(95 \%)$ & $p$ value \\
\hline \multirow[t]{5}{*}{ Fruit intake g/day } & Q1 (< 162.05) & 1.31 & $(1.10-1.55)$ & $0.002^{*}$ & 1.25 & $(1.03-1.52$ & $0.021^{*}$ & 1.18 & $(0.97-1.44)$ & 0.094 \\
\hline & Q2 (162.06-287.5) & 1.10 & $(0.93-1.30)$ & 0.272 & 1.07 & $(0.90-1.28)$ & 0.432 & 1.00 & $(0.84-1.20)$ & 0.973 \\
\hline & Q3 (287.51-470.9) & 1.17 & $(0.99-1.37)$ & 0.062 & 1.18 & $(0.99-1.40)$ & 0.060 & 1.12 & $(0.94-1.33)$ & 0.222 \\
\hline & Q4 (> 470.09) & 1 & & & 1 & & & 1 & & \\
\hline & Trend & & & $0.008^{*}$ & & & 0.071 & & & 0.239 \\
\hline \multirow[t]{6}{*}{ Vegetable intake g/day } & Q1 $(<92.86)$ & 1.22 & $(1.03-1.45)$ & $0.019^{*}$ & 1.33 & $(1.10-1.60)$ & $0.003^{*}$ & 1.25 & $(1.03-1.51)$ & $0.024^{*}$ \\
\hline & Q2 (92.87-156.95) & 1.22 & $(1.04-1.44)$ & $0.017^{\star}$ & 1.31 & $(1.09-1.56)$ & $0.003^{*}$ & 1.25 & $(1.04-1.50)$ & $0.016^{*}$ \\
\hline & Q3 (156.96-255.73) & 1.15 & $(0.98-1.36)$ & 0.088 & 1.23 & $(1.04-1.46)$ & $0.018^{\star}$ & 1.17 & $(0.98-1.40)$ & 0.076 \\
\hline & Q4 (> 255.73) & 1 & & & 1 & & & 1 & & \\
\hline & Trend & & & $0.015^{\star}$ & & & $0.003^{*}$ & & & $0.020^{*}$ \\
\hline & Q1 $(<293.46)$ & 1.29 & $(1.08-1.53)$ & $0.004^{*}$ & 1.29 & $(1.06-1.57)$ & $0.013^{*}$ & 1.24 & $(1.01-1.52)$ & $0.036^{*}$ \\
\hline \multirow{4}{*}{$\begin{array}{l}\text { Fruit and vegetable } \\
\text { intake g/day }\end{array}$} & Q2 (293.47-463.71) & 1.21 & $(1.02-1.42)$ & $0.027^{*}$ & 1.24 & $(1.04-1.49)$ & $0.019^{*}$ & 1.20 & $(1.00-1.44)$ & 0.055 \\
\hline & Q3 (463.72-713.72) & 1.09 & $(0.93-1.28)$ & 0.301 & 1.10 & $(0.93-1.31)$ & 0.272 & 1.08 & $(0.90-1.28)$ & 0.428 \\
\hline & Q4 (> 713.72) & 1 & & & 1 & & & 1 & & \\
\hline & Trend & & & $0.002^{*}$ & & & $0.006^{\star}$ & & & $0.020^{*}$ \\
\hline
\end{tabular}

${ }^{*} \mathrm{p}<0.05$; Model 1 adjusted for age and sex. Model 2 further adjusted for education, economic activity, marital status, material deprivation, smoking status, binge drinking of alcohol, and physical activity, and the self-reported doctor diagnosed high blood pressure (yes, no), diabetes mellitus (yes, no), previous heart attack/acute myocardial infarction, angina/ischemic heart disease, stroke, cancer, and long-term health problems that needed medical treatment.related to health status. Model 3 further adjusted for the total energy intake in megajoule (MJ), and SRH from wave 1. 


\section{Supplementary materials}

\section{Table S1 List of fruits and vegetables included in analysis}

\section{Food Group}

Fruits

Vegetables

\section{Items}

apples, pears, oranges, mandarins, lemons, grapefruit, peaches, apricots, plums, cherries, strawberries, raspberries, red currant, black currant, blueberries, gooseberry, kiwi, melon, pineapple, bananas, grapes, tinned or bottled fruit, dried fruit green salad (lettuce), spinach, cabbage, beans, lentils, dried peas, green beans, green peas, cauliflower, broccoli, kohlrabi, radish, carrots, celeriac, parsley, onion, leeks, garlic, cucumbers, aubergine, pumpkin/courgette, peppers, tomatoes, corn, sauerkraut, pickled vegetables or gherkins, mushrooms, mixed frozen vegetable, soya meat 
Table S2 Fully-adjusted Model 3 for combined fruit and vegetable intake with all the covariates

\begin{tabular}{|c|c|c|c|c|}
\hline & & OR & $\mathrm{Cl}(95 \%)$ & $p$ value \\
\hline \multirow[t]{5}{*}{ Age } & $45-49$ & 1 & & \\
\hline & $50-54$ & 0.98 & $(0.80-1.21)$ & 0.874 \\
\hline & $55-59$ & 0.94 & $(0.75-1.18)$ & 0.619 \\
\hline & $60-64$ & 0.97 & $(0.74-1.28)$ & 0.824 \\
\hline & $65-69$ & 1.11 & $(0.83-1.50)$ & 0.477 \\
\hline \multirow[t]{2}{*}{ Sex } & Female & 1 & & \\
\hline & Male & 0.95 & $(0.81-1.10)$ & 0.488 \\
\hline \multirow[t]{3}{*}{ Self-rated health W1 } & Very good & 0.04 & $(0.03-0.06)$ & $<0.001^{*}$ \\
\hline & Good & 0.25 & $(0.21-0.29)$ & $<0.001^{*}$ \\
\hline & Average & 1 & & \\
\hline \multirow[t]{4}{*}{ Education } & Primary or less & 1.36 & $(1.06-1.81)$ & $0.018^{*}$ \\
\hline & Vocational & 1.13 & $(0.93-1.37)$ & 0.221 \\
\hline & Secondary & 1.05 & $(0.88-1.23)$ & 0.582 \\
\hline & University & 1 & & \\
\hline \multirow[t]{5}{*}{ Economic activity } & Employed & 1 & & \\
\hline & Entrepreneur & 0.85 & $(0.67-1.08)$ & 0.193 \\
\hline & Pensioner. still employed & 1.16 & $(0.87-1.54)$ & 0.306 \\
\hline & Pensioner. not employed & 1.39 & $(1.11-1.75)$ & $0.004^{*}$ \\
\hline & Housewife. unemployed & 1.06 & $(0.71-1.58)$ & 0.776 \\
\hline \multirow[t]{4}{*}{ Marital status } & Married/Cohabiting & 1 & & \\
\hline & Single & 1.33 & $(0.90-1.97)$ & 0.152 \\
\hline & Divorced & 0.97 & $(0.80-1.18)$ & 0.746 \\
\hline & Widowed & 1.04 & $(0.83-1.31)$ & 0.737 \\
\hline \multirow[t]{3}{*}{ Material deprivation } & Without problems & 1 & & \\
\hline & Few problems & 1.10 & $(0.95-1.28)$ & 0.221 \\
\hline & With problems & 1.25 & $(1.06-1.47)$ & $0.008^{*}$ \\
\hline \multirow[t]{3}{*}{ Smoking status } & Smoker & 1.07 & $(0.91-1.26)$ & 0.389 \\
\hline & Ex-smoker & 1.04 & $(0.90-1.21)$ & 0.583 \\
\hline & Non-smoker & 1 & & \\
\hline \multirow[t]{2}{*}{ Binge drinking } & No & 1 & & \\
\hline & Yes & 1.16 & $(0.98-1.36)$ & 0.078 \\
\hline \multirow[t]{4}{*}{ Physical activity } & No activity & 1.19 & $(1.00-1.41)$ & $0.046^{*}$ \\
\hline & Low & 1.19 & $(0.99-1.42)$ & 0.058 \\
\hline & Medium & 0.96 & $(0.81-1.14)$ & 0.640 \\
\hline & Intensive & 1 & & \\
\hline Total energy intake (MJ) & & 1.02 & $(0.99-1.04)$ & 0.176 \\
\hline \multirow[t]{2}{*}{ High blood pressure } & No & 1 & & \\
\hline & Yes & 1.36 & $(1.19-1.56)$ & $<0.001^{*}$ \\
\hline \multirow[t]{2}{*}{ Diabetes mellitus } & No & 1 & & \\
\hline & Yes & 1.59 & $(1.28-1.98)$ & $<0.001^{*}$ \\
\hline \multirow[t]{2}{*}{ Long-term health problems } & No & 1 & & \\
\hline & Yes & 1.47 & $(1.27-1.70)$ & $<0.001^{*}$ \\
\hline \multirow[t]{2}{*}{ Diagnosed/hospitalised HA/Ml** } & No & 1 & & \\
\hline & Yes & 0.91 & $(0.61-1.36)$ & 0.652 \\
\hline Diagnosed/hospitalised A/IHD*** & No & 1 & & \\
\hline
\end{tabular}




$\begin{array}{lllll} & \text { Yes } & 1.12 & (0.75-1.69) & 0.578 \\ \text { Diagnosed/hospitalised stroke } & \text { No } & 1 & & \\ & \text { Yes } & 0.80 & (0.48-1.32) & 0.380 \\ \text { Diagnosed/hospitalised cancer } & \text { No } & 1 & & \\ & \text { Yes } & 1.21 & (0.90-1.64) & 0.210\end{array}$

**Diagnosed/hospitalised for heart attack (HA)/acute myocardial infarction (MI)

***Diagnosed/hospitalised for angina (A)/ischaemic heart disease (IHD) 